\title{
SINGULAR INTEGRAL INEQUALITIES AND NATURAL REGULARIZATIONS
}

\section{Yoshihiro Sawano, Masato Yamada and Saburou Saitoh}

Abstract. We shall introduce natural regularizations for singular integrals from the viewpoint of numerical treatments and establish very good error estimates (fundamental inequalities for potentials) for the regularizations.

Mathematics subject classification (2010): 26D15.

Keywords and phrases: Singular integral, fractional integral, Riesz potential, Newton potential, logarithm potential, natural regularization, error estimate, numerical analysis, inequalities, potential inequalities.

\section{REFERENCES}

[1] A. P. CALderón, Spaces between $L^{1}$ and $L^{\infty}$ and the theorem of Marcinkiewicz, Studia Math., 26 (1966), 273-299.

[2] A. P. CAlderón And A. Zygmund, A note on the interpolation of sublinear operations, Amer. J. Math., 78 (1956), 282-288.

[3] A. P. Calderón AND A. Zygmund, On singular integrals, Amer. J. Math., 78 (1956), 289-309.

[4] A. P. CAlderón AND A. Zygmund, Singular integral operators and differential equations, Amer. J. Math., 79 (1957), 901-921.

[5] J. Duoandikoetxea, C. Michael and J.L. Rubio De Francia, Maximal operators related to the Radon transform and the Calderón-Zygmund method of rotations, Duke Math. J., 531 (1986), 189-209.

[6] H. Gunawan AND ERIDANI, Fractional integrals and generalized Olsen inequalities, Kyungpook Math. J. (to appear).

[7] ERIDANI, H.GUNAWAN AND E. NAKAI, On generalized fractional integral operators, Sci. Math. Japon., 2004.

[8] L. HöRMANDER, An introduction to complex analysis in several variables, North Holland, Amsterdam, 1991.

[9] Y. Mizuta And T. Shimomura, Sobolev's inequality for Riesz potentials of functions in Morrey spaces of integral form, Math. Nachr (to appear).

[10] Y. Mizuta And T. Shimomura, Exponential integrability for Riesz potentials of functions in Orlicz classes, Hiroshima Math. J., 28 (1998), 355-371.

[11] Y. Mizuta, T. Shimomura And T. Sobukawa, Sobolev's inequality for Riesz potentials of functions in non-doubling Morrey spaces, Osaka Math. J. (to appear).

[12] E. NAKAI, Generalized fractional integrals on Orlicz-Morrey Spaces, Proceedings on Banach and Function spaces, Kitakyushu, Japan, Oct. 2-4, 2003, 323-333.

[13] E. NAKaI, Generalized fractional integrals on Orlicz-Morrey spaces, Proceedings of the International Symposium on Banach and Function spaces, Yokohama Publishers.

[14] F. Nazarov, S. Treil and A. Volberg, Weak type estimates and Cotlar inequalities for Calderön-Zygmund operators on nonhomogeneous spaces, Internat. Math. Res. Notices (1998), $463-$ 487.

[15] S. Saitoh, Representations of inverse functions, Proc. Amer. Math. Soc., 125 (1997), 3633-3639.

[16] S. SAitoH, Integral Transforms, Reproducing Kernels and their Applications, Pitman Research Notes in Mathematics Series, 369 (1997), Addison Wesley Longman, UK. 
[17] Y. Sawano, T. Sobukawa And H. Tanaka, Limiting case of the boundedness of fractional integral operators on nonhomogeneous space, J. Inequal. Appl. (2006), Art. ID 92470, 16 pp.

[18] T. Shimomura, $L^{q}$-mean limits of Taylor's expansion of Riesz potentials of functions in Orlicz spaces, Hiroshima Math. J., 27 (1997), 159-175.

[19] T. Shimomura And Y. Mizuta, Taylor expansion of Riesz potentials, Hiroshima Math. J., 25 (1995), 595-621.

[20] S. Sugano AND H. TANAKa, Boundedness of fractional integral operators on generalized Morrey spaces, Sci. Math. Jpn., 583 (2003), 531-540.

[21] E. M. SteIn, Harmonic Analysis: Real-Variable Methods, Orthogonality, and Oscillatory Integrals, Princeton Univ. Press, 1993.

[22] M. Yamada, T. MatsuURa And S. Saitoh, Representations of inverse functions by the integral transform with the sign kernel, Fract. Calc. Appl. Anal., 10 (2007), 161-168.

[23] M. Yamada And S. Saitoh, Identifications of non-linear systems, J. Comput. Math. Optim., 41 (2008), 47-60.

[24] M. YAmAda AND S. SAItoh, Numerical solutions of 2-nonlinear simultaneous equations, Appl. Anal. (to appear). 